\title{
A Tool to Support PLM Teaching in Universities
}

\author{
Joel Sauza Bedolla ${ }^{1}$, Francesco Ricci ${ }^{1}$, Javier Martinez Gomez ${ }^{1,2}$, and Paolo Chiabert ${ }^{1}$ \\ ${ }^{1}$ Politecnico di Torino, C.so Duca degli Abruzzi 24, Torino 10129, Italy \\ ${ }^{2}$ Universidad Industrial de Santander, Calle 9 Cra.27, Bucaramanga, Colombia
}

\begin{abstract}
Product Lifecycle Management (PLM) is the business paradigm that companies employ as a key for success. Currently, industry needs people at working in a collaborative environment with PLM, since this is the challenge they will be facing in the global economy. At the moment this professional profile is not common in the work market and there is therefore, an educational gap. As well as technical knowledge, new engineers must be familiar with the PLM philosophy and use its tools to work effectively in collaboration with teams around the world. In order to bridge this gap, this paper presents a visualization model that gives the guidelines for a proper understanding of the $\mathrm{CAD}$ design activities executed in a PLM system. The proposed model, which follows the work method of a large car manufacturer, has been successfully tested and applied in a university course.
\end{abstract}

\section{Introduction}

Nowadays, companies operate over several continents. A designer in one country can specify a product that is then made in another and probably assembled in yet another. Furthermore, the worldwide business environment is experiencing an increase in the use of out-sourcing and sub-contracting. The globalization of markets and augmented consumer sophistication have led to a rise in the variety of products that customers demand and a consequent growth in the number of variants of any given product line that a manufacturer must supply [1]. There is also an increasing demand for outstanding functions of products at a low price [2].

Organizations communicate routinely to and from their supply chain and within their own organization. Most of the information is created, stored and shared as electronic files $[3,4]$. An example of this is the extensive use of CAD/CAM-systems in industry; it has become an important and widely used technology. Companies have invested large amounts in these systems and are becoming very dependent on CAD technology for the development of new products [5]. These circumstances have changed the traditional means of communication in industry in recent years.

In such a global market, PLM is the only stable channel of communication. PLM deals with the creation, modification, and exchange of product information throughout the product's lifecycle [6]. PLM is an essential tool for coping with the challenges of more demanding global competition, ever-shortening product and component lifecycles and growing customer needs [7]. 
The main use of PLM include aerospace, defense, automotive, electronics/high tech, fabrication and assembly industries [8]. Most PLM knowledge is within industry and universities are now being asked to prepare future graduates with basic knowledge of PLM. The challenge for universities is to train a highly skilled pool of engineers and professionals able to work and communicate effectively in PLM systems.

Politecnico di Torino recently became aware of this situation and decided to deploy PLM theories in teaching design practices using a market leader PLM system. Proper understanding of the PLM philosophy requires awareness of the instrument (software) functionality and the methodology of use.

Torino is famous primarily for its car manufacturing industry. This industry, due to its complexity, depends almost exclusively on PLM technology. It is then extremely important to prepare the students of Automotive Engineering on the way industry works. Since the university did not have that knowledge, a collaboration agreement with FIAT FGA was established.

The course of Fundamentals of Machining Design and Drawing (FMDD) aims to provide students with basic knowledge of the technologies used in mechanical design aided systems in order to enable an efficient collaboration among designers. This course was the ideal test bench to introduce a PLM based program. This program is inspired by FIAT work method.

PLM goes beyond CAD and PDM applications and there are several examples in literature of collaborative product development curriculum [9-11]. However due to the course contents and credits, it was not possible to introduce an entire PLM approach. CAD integration in a PLM system is envisaged as the first step of an ambitious project that aims at introducing different PLM-based exercises in different courses (i.e. the clamp used in this exercise will be reused in the Manufacturing assemblies course to design a manufacturing cell).

There are several methods to represents processes. However, certain complex data, when visualized graphically, convey far more information to the reader than the raw data itself [12]. We therefore developed a formal Visualization Model (VM) of enterprise processes that offers a graphic representation of the main elements of a product lifecycle (processes, people, tools, skills and information) and makes it possible to address them on an overall level [13].

The VM proved to be an useful tool to represent industrial processes and to transfer them to PLM systems. Moreover, it was exceptionally effective as a training method for explaining the concepts of information management to persons new to this subject. We therefore decided to use the VM as a tool to explain PLM.

\section{Pilot Group}

Introducing a new tool, as complex as a PLM system with an integrated CAD software, in a university course without a proper testing phase would have been too risky. For this reason it was decided to try the contents with a Pilot Group. A small group of students from Automotive Engineering joined the Voluntary Educational Program (VEP) "PLM in automotive industry" to test the contents of the course and the 
software platform that that makes it possible to integrate machine design in a PLM framework.

At the end of the VEP course some important issues arose. The need for customization the PLM system was evident. The direct use of existing features did not guarantee the correct representation of the desired design process. Over a seven months period different modifications were made to the PLM platform at different levels (client options, site variables, access rules, server manager). Moreover, from the didactic point of view, it was recognized the need for a model that accounts for the principal concepts of PLM and serve as a guide for students.

\section{Course Re-Definition}

\section{Epistemology}

A packed curriculum leaves little time for students to acquire a deep understanding of the subject or to develop life-long skills such as critical thinking, problem solving, and communication [14]. This course is envisioned to encourage team work using industrial instruments that foster the learning process. Rather than depending on a teacher-centered approach, the course is based on an active process (problem solving and interaction) that relates or builds upon knowledge previously acquired by students. This constructivist learning approach increases critical thinking and active learning.

\section{Case Study}

A case study, an industrial clamp fixture (Fig. 1), was carefully chosen among other proposals. Despite a relative easy geometry it presents a good number of delicate design issues. Even though the clamp fixture is not a car component, it is employed to assemble and weld the car body elements in the production line.

\section{Students Background}

FMDD is a mandatory course of the third year at the Bachelor program of Automotive Engineering. Students have acquired, on previous courses, the basic knowledge and skills for interpreting unambiguously and correctly drawings of parts and assemblies.

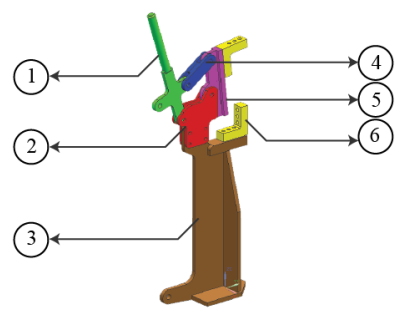

\begin{tabular}{|r|l|}
\hline \multicolumn{2}{|c|}{ Parts description } \\
\hline 1 & Operating lever \\
\hline 2 & Top fixing plate \\
\hline 3 & Support \\
\hline 4 & Swingig transmission \\
\hline 5 & Rotary support \\
\hline 6 & Block fixing brackts \\
\hline
\end{tabular}

Fig. 1. Industrial Clamp Fixture 


\section{Situational Constraints}

Automotive Engineering is an international program taught in English. It hosts 155 students (per year) from all over the world. For the year 2012, nearly 100 students were expected to attend the FMDD course.

FMDD is a 4 credit course, which means 40 hours of frontal teaching. The planned lectures were divided in 18 hours of theoretical lectures and 22 hours of training on PLM integrated CAD system.

The Mirafiori campus has three laboratories with different capacities (from 30 to 50 computer). The available software for the exercise is NX 7.5 as CAD system and Teamcenter 8.0 (TC) for Product Data Management.

\section{Learning Objectives}

The main objective of the course is to teach students how to work semi-autonomously on recurring design tasks using a PLM instrument. Students learn how to carry out a collaborative product design using an integrated work method.

In order to do this, every student first realize the clamp assembly individually and then within a 6 people team where he performs, in turn, the role of member and teamleader. Both exercises are based on the use of the same parts yet different purposes are assessed. During the single user exercise, every student is asked to design all parts of the clamp and to assemble them using standard fasteners. Efforts are focused on the CAD system while, at the same time, students acquaint confidence with the TC environment.

On the other hand, during teamwork, students reuse the parts created in the single user exercise and focus their attention on the information exchange (the main aim of a PLM system). A design error is intentionally introduced in one of the parts that has to be identified and fixed by students. Here is where the previous design knowledge is assessed and students develop the collaborative skills. In this paper only the team exercise is presented.

\section{$4 \quad$ Methodological Strategy}

The VM follows a Top-Down strategy, breaking down the product lifecycle to gain insight into its Process Areas (PA). Each PA characterize the aspects of product development to be covered by organizational processes and can be expressed as a workflow. Every component of the workflow is then described in a Decomposition Diagram (DD) that contains the information of who (role) is responsible of a workproduct (item) generated with an activity that requires particular tools and skills. The methodology of the VM is presented in Fig. 2a.

The visual representation provided by VM makes it particularly suitable for didactic purposes. It works as an interactive guide leading the students through the principal concepts of PLM-based design. 


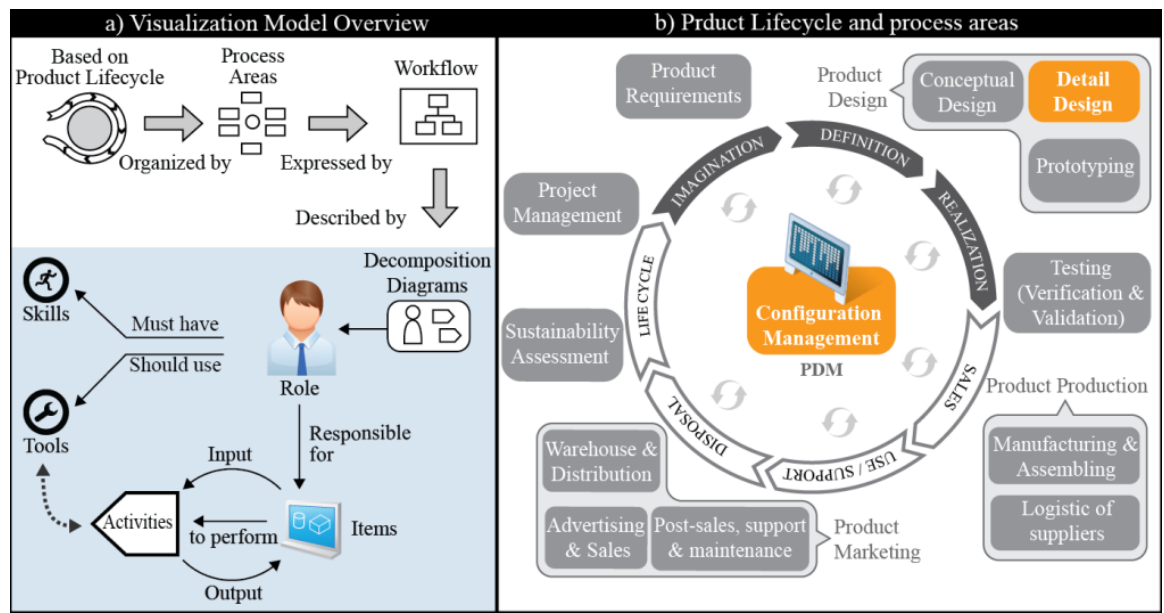

Fig. 2. a) Visualization model overview b)Product lifecycle and Process Areas

\section{Product Lifecycle and Process Areas}

The FMDD course focuses on the product design process area, with particular attention for the activities related with detail design. This implies that the process is located at the beginning of product life, during product definition phase (Fig. 2b). Being the heart of the product lifecycle, the configuration management controls all data generated during the development of any activity.

\section{Workflow}

Fig. 3 presents the team exercise workflow. The process starts with the creation of the clamp Product Structure; the product Bill of Materials (BOM). Then, every student, performing the team leader role, requires the clamp parts (task assignment) to other team members. After all parts are released, the team leader assembles the parts and releases the clamp assembly. It is the team-leader responsibility to identify the design error (intentionally introduced by the teacher) in the assembly and manage the assembly modification (change management).

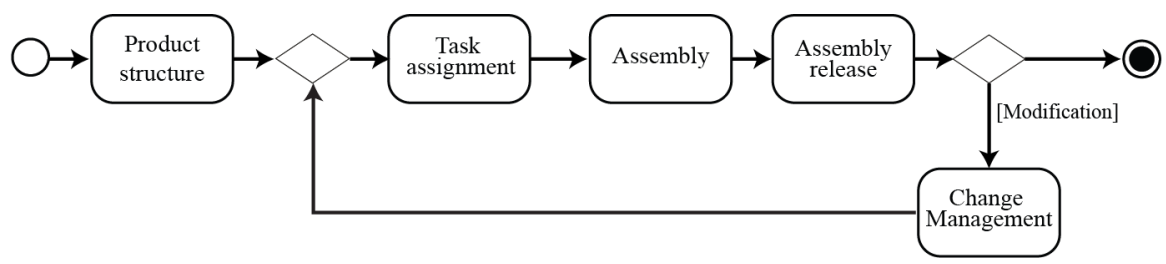

Fig. 3. Team exercise workflow 


\section{Decomposition Diagrams}

The product structure is created in the structure manager of TC. However, the resulting BOM is recognized only in TC and the CAD system must be synchronized with the PDM. For this reason Fig. 5a presents two activities, the creation of the product structure and manage pending components, where issues between the instruments are solved. The process does not need any inputs to start since it is the first activity of the process. The workproduct of the activity is the Item Assembly which is composed by the 6 principal parts of the clamp.

Every student during teamwork will perform two roles: team leader and team member. As team leader the student is responsible of gathering parts from team members through the use of an automatic TC workflow (Fig. 4). As team member the student is asked to perform a component design.

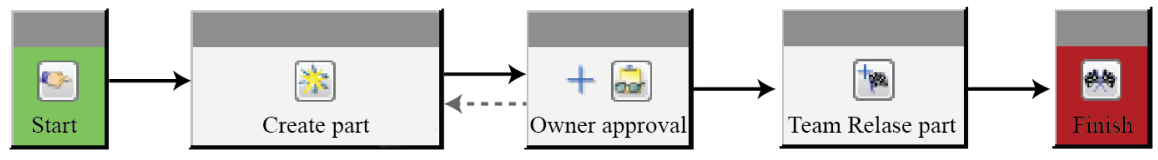

Fig. 4. Team release part TC workflow

Students exchange information following a permutation design. Every team member receives one part draft plus instructions to realize the 3D model in integrated NX. At the end of the "workflow execution" the part is released and accounted in the PLM system. The "workflow assignment" and "workflow follow-up" are performed by the team leader while the "workflow execution" is an activity allocated to team members (Fig. 5b).

The following step is to assemble the modelled parts using standard fasteners (screw, nuts and pins) previously loaded into TC. Standard fasteners are retrieved by team leader using the TC item-search function. Subsequently, team leader duplicates the necessary parts and modifies the product structure in the TC structure manager. The assembly is then constrained and finally set to a precise configuration. The five activities are presented in Fig. 6a. At this point the assembly is complete and can be released (Fig. 6b) using an automatic TC workflow (Team release assembly).

Once the assembly is released, the teacher alerts students that the clamp kinematic is compromised by a design error they have to fix. Team work autonomously to solve the problem. Students increase their collaboration skills and become acquainted with communication means offered by the PLM system. When the team agrees on the design change, the team leader creates a revision of the assembly and part(s) (Fig. 6c). He then coordinates the activities using the workflow of Fig. 3. 
a) DD Product Structure

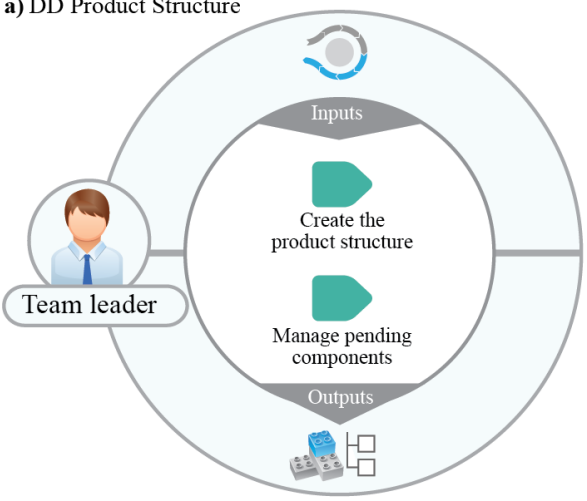

b) DD Task assignment
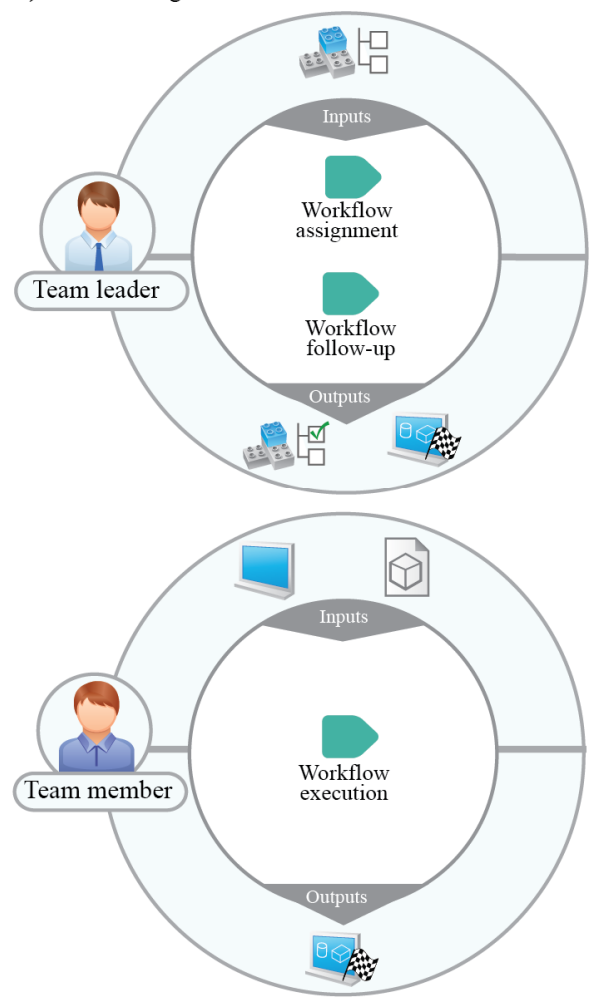

\section{Items \\ Description}

\begin{tabular}{|c|l|}
\hline & $\begin{array}{l}\text { Visualization Model contain a } \\
\text { specific guideline about work } \\
\text { to be performed. }\end{array}$ \\
\hline $\begin{aligned} \text { Item assembly (empty) is the product } \\
\text { structure with the following empty } \\
\text { items: } \\
\text { Support, top fixing plate, rotary } \\
\text { support, swingig transmission device, } \\
\text { block fixing brackets and operating } \\
\text { lever }\end{aligned}$ \\
\hline Skills & $\begin{array}{l}\text { What is item/ item revision/dataset. } \\
\text { How to create Items. }\end{array}$ \\
\hline What is Product structure \\
\hline Tools & $\begin{array}{l}\text { Teamcenter } \\
\text { Structure manager } \\
\text { Integrated NX }\end{array}$ \\
\hline
\end{tabular}

\begin{tabular}{|c|c|}
\hline Items & Description \\
\hline$\therefore: \frac{-\sqrt{v}}{\square}$ & $\begin{array}{l}\text { Item assembly with all 3D models } \\
\text { inside. }\end{array}$ \\
\hline & $\begin{array}{l}\text { 3D models released of each assembly } \\
\text { part: Support, top fixing plate, rotary } \\
\text { support, swingig transmission device, } \\
\text { block fixing brackets and operating } \\
\text { lever }\end{array}$ \\
\hline Skills & $\begin{array}{l}\text { What is product structure } \\
\text { TC Integration. }\end{array}$ \\
\hline Tools & $\begin{array}{l}\text { Teamcenter Structure manager } \\
\text { Integrated NX } \\
\text { WF viewer }\end{array}$ \\
\hline
\end{tabular}

\begin{tabular}{|c|l|}
\hline Items & \multicolumn{1}{c|}{ Description } \\
\hline & $\begin{array}{l}\text { Item part of the following parts: } \\
\text { Support, top fixing plate, rotary } \\
\text { support, swingig transmission device, } \\
\text { block fixing brackets and operating } \\
\text { lever }\end{array}$ \\
\hline Skills & $\begin{array}{l}\text { Drafts of each assembly part: } \\
\text { Support, top fixing plate, rotary } \\
\text { support, swingig transmission device, } \\
\text { block fixing brackets and operating } \\
\text { lever }\end{array}$ \\
\hline C & $\begin{array}{l}\text { What is product structure } \\
\text { TC Integration. } \\
\text { NX modelling. }\end{array}$ \\
\hline Tools & $\begin{array}{l}\text { Teamcenter Structure manager } \\
\text { Integrated NX }\end{array}$ \\
\hline
\end{tabular}

Fig. 5. Decomposition Diagrams of a)Product Structure b)Task assignment 
a) DD Assembly

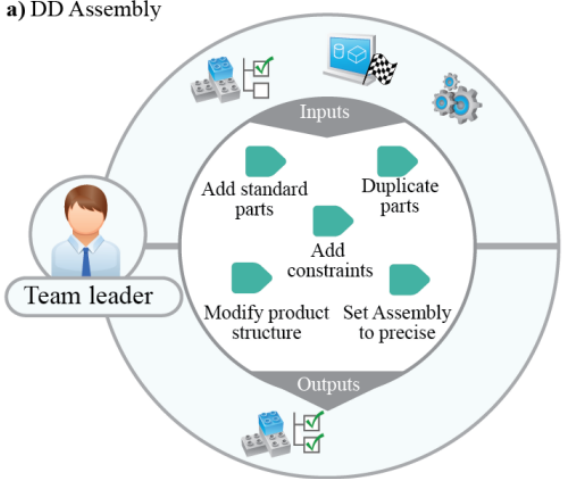

b) DD Task assignment

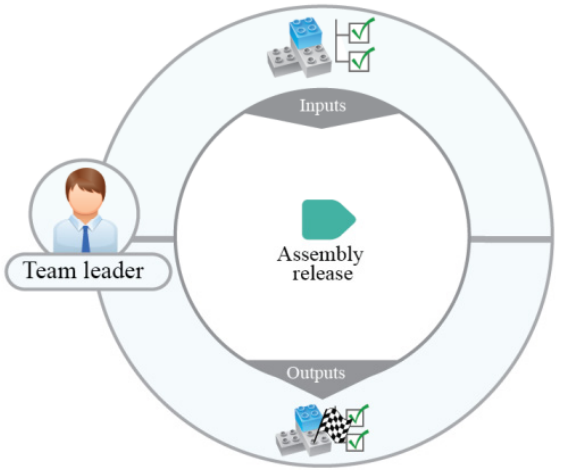

c) DD Change Management

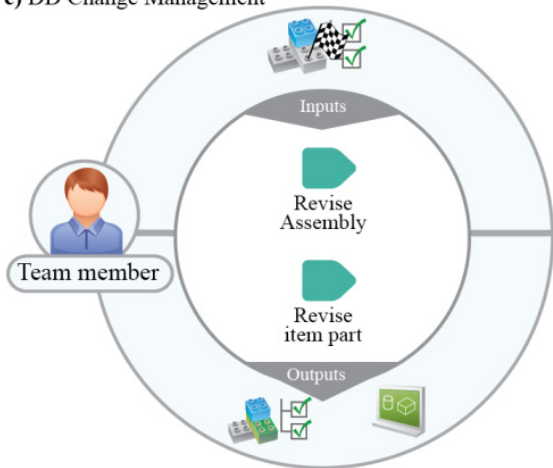

\section{Items Description}

\begin{tabular}{|c|l|}
\hline & $\begin{array}{l}\text { Standard parts: Screw M8x34, } \\
\text { Screw M8x30, Screw M10x34, Nut } \\
\text { M8, Nut M10, Pin 6x24, Pin 6x30. }\end{array}$ \\
\hline & $\begin{array}{l}\text { Item assembly with all items parts } \\
\text { released and duplicated, and } \\
\text { standards parts release inside. }\end{array}$ \\
\hline \hline \begin{tabular}{|c|} 
Skills \\
Tools
\end{tabular} & $\begin{array}{l}\text { Assembly constraints } \\
\text { Item search } \\
\text { Product structure }\end{array}$ \\
\hline
\end{tabular}

\section{Items Description}

\begin{tabular}{|c|l|}
\hline & $\begin{array}{l}\text { Item assembly released with all } \\
\text { 3D models and standard parts } \\
\text { inside. }\end{array}$ \\
\hline \hline $\begin{array}{c}\text { Skills } \\
\text { Sk }\end{array}$ & $\begin{array}{l}\text { WF viewer } \\
\text { Product structure }\end{array}$ \\
\hline Tools & WF viewer \\
\hline
\end{tabular}

\begin{tabular}{|c|l|}
\hline Items & \multicolumn{1}{|c|}{ Description } \\
\hline & $\begin{array}{l}\text { Item assembly revision is a new } \\
\text { version of the item assembly. } \\
\text { a item part. }\end{array}$ \\
\hline \hline Skills & $\begin{array}{l}\text { Change Management } \\
\text { Revision rules }\end{array}$ \\
\hline Tools & Product structure \\
\hline
\end{tabular}

Fig. 6. Decomposition Diagrams of a)Assembly b)Task Assignment c) Change management

\section{Activity Sheets}

The model is completed with a more detailed description of the activities presented in a resume sheet. As an example, Table 1 presents the activity "Set assembly to precise" of the DD Assembly. At this level of detail there is a thorough description of the commands students must use in TC (or NX). It was decided to improve the clarity of instructions and repeatability of tasks by attaching videos to the VM. 
Table 1. Activity sheet "Set assembly to precise"

\begin{tabular}{|l|l|}
\hline Target: & $\begin{array}{l}\text { Set assembly to precise } \\
\text { Operation: }\end{array}$ \\
Set to precise the final assembly & $\begin{array}{l}\text { Open the Assembly item } \\
\text { Go to Edit } \rightarrow \text { Toggle Precise/Imprecise }\end{array}$ \\
\hline $\begin{array}{l}\text { Input items: } \\
\text { Product structure (Assembly }+7 \text { standard parts) }\end{array}$ & $\begin{array}{l}\text { Output items: } \\
\text { Product structure (Assembly }+22 \text { standard parts) }\end{array}$ \\
\hline $\begin{array}{l}\text { Role: } \\
\text { Student }\end{array}$ & $\begin{array}{l}\text { Attached information: } \\
\text { Video: } 13 \_S e t\end{array}$ \\
\hline
\end{tabular}

\section{Material}

The resulting models were uploaded to the course webpage where all students can access them. The single user VM consists of a workflow, 7 Decomposition Diagrams and 23 activity sheets while the team VM consists of 5 Decomposition Diagrams and 13 activity sheets. Both VMs are supported by 25 videos.

\section{$5 \quad$ Results}

At the end of the course an anonymous questionnaire (Likert scale) was used for measuring perception of the VM model (10 questions) and the general contents of the course (further 10 questions). The more relevant aspects are listed below:

- Positive Aspects

- Students agree that the course achieved its objectives.

- Students have a fairly clear perception of the way product design is handled in a collaborative environment (Fig. 7a).

- $\quad$ Students found the VM a useful support for understanding PLM (Fig. 7b).

a)

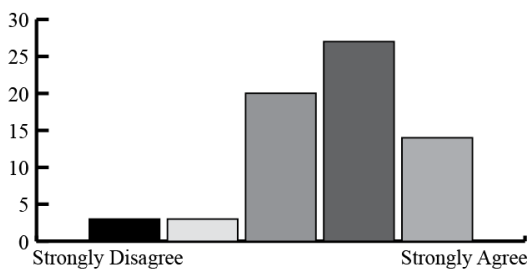

b)

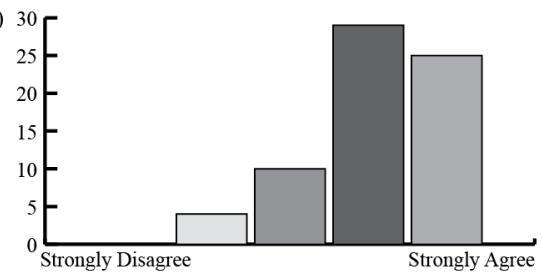

Fig. 7. Answers to questions: a) The PLM experience enlightened me on how product design is handled in a collaborative way by large companies b), I think the VM helps to understand PLM

- Negative Aspects

- Too many interruptions due to Teamcenter crashes have been an obstacle for learning.

- The availability of informatics laboratories for exercising was insufficient.

- Students think that there was some inconsistency in the VM.

Several recommendations were outlined by students and are now being considering to improve next year course. Special attention has been given to Teamcenter for the 
several drawbacks that caused service interruption during the course. A cause-root analysis was performed and all problems were solved.

\section{Conclusions}

The FMDD course successfully integrated the CAD designing activity in a PLM system using a work methodology inspired by FIAT. A class of 99 students of different nationalities used the VM as a guide for its work in the PLM environment. All students successfully completed the single and team exercise. All activities were fairly clear and the use of videos as a support has simplified the explanations and reduced the misinterpretations.

The VM has proven to be an extremely effective training tool. It drove the actions of students, clarifying the activities at every step, and training them to work in a collaborative environment. Given the scarcity of PLM-specialized professionals on the work market, Politecnico di Torino is contributing to bridge the educational gap on PLM.

\section{References}

1. Swaminathan, J.M., Nitsch, T.R.: Managing Product Variety in Automobile Assembly: The Importance of the Sequencing Point. Interfaces 37(4), 324-333 (2007)

2. ISO/TC-213, Business Plan Dimensional and geometrical product specifications and verification (2004), http: / / isotc213.ds.dk/213business $\% 20 p l a n . p d f$

3. Baldwin, A.N., Thorpe, A., Carter, C.: The use of electronic information exchange on construction alliance projects. Automation in Construction 8(6) (1999)

4. Hill, C.A., Scudder, G.D.: The use of electronic data interchange for supply chain coordination in the food industry. Journal of Operations Management 20(4) (2002)

5. Robertson, D., Allen, T.J.: CAD System Use and Engineering Performance. IEEE Transactions on Engineering Management 40(3) (1993)

6. Srinivasan, V.: An integration framework for product lifecycle management. ComputerAided Design 43, 464-478 (2011)

7. Saaksvuori, A., Immonen, A.: Product Lifecycle Management, 3rd edn. Springer (2008)

8. CIMdata, Economic Benefits of PLM-Enabled Collaboration. CIMdata (2009)

9. Maranzana, N., Segonds, F., Lesage, F., Nelson, J.: Collaborative Design Tools: A Comparison Between Free Software and PLM Solutions in Engineering Education. In: Rivest, L., Bouras, A., Louhichi, B. (eds.) PLM 2012. IFIP AICT, vol. 388, pp. 547-558. Springer, Heidelberg (2012)

10. Segonds, F., Maranzana, N., Veron, P., Aoussat, A.: Collaborative Reverse Engineering Design Experiment Using PLM Solutions. International Journal of Engineering Education (2011)

11. Vila, C., Abellán-Nebot, J.V., Estruch, A.M., Siller, H.R.: Collaborative product development experience in a senior Integrated manufacturing course. International Journal of Engineering Education 25(5), 886-899 (2009)

12. Quatrani, T.: Visual modeling with Rational Rose, and UML. Pearson Education (2000)

13. Chiabert, P., Lombardi, F., Sauza Bedolla, J., Martinez Gomez, J.: Visualization Model for Product Lifecycle Management. Annals of Faculty Engineering Hunedoara 11(1) (2013)

14. Lujan, H.L., DiCarlo, S.E.: Too much teaching, not enough learning: what is the solution? Advances in Physiology Education 30, 17-22 (2006) 